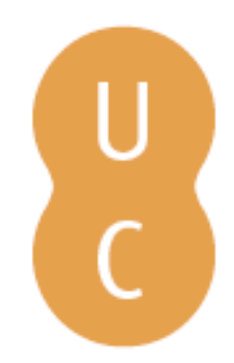

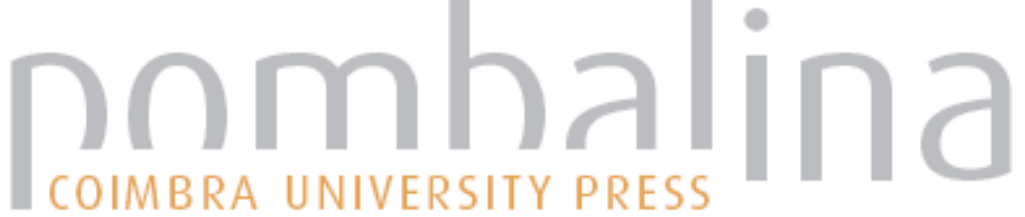

\section{A biblioteca e o meu mundo}

\author{
Autor(es): $\quad$ Torgal, Luís Reis
}

Publicado por: Imprensa da Universidade de Coimbra

URL

persistente: URI:http://hdl.handle.net/10316.2/36993

DOI: $\quad$ DOI:http://dx.doi.org/10.14195/978-989-26-1045-0_22

Accessed : $\quad$ 26-Apr-2023 02:39:46

A navegação consulta e descarregamento dos títulos inseridos nas Bibliotecas Digitais UC Digitalis, UC Pombalina e UC Impactum, pressupõem a aceitação plena e sem reservas dos Termos e Condições de Uso destas Bibliotecas Digitais, disponíveis em https://digitalis.uc.pt/pt-pt/termos.

Conforme exposto nos referidos Termos e Condições de Uso, o descarregamento de títulos de acesso restrito requer uma licença válida de autorização devendo o utilizador aceder ao(s) documento(s) a partir de um endereço de IP da instituição detentora da supramencionada licença.

Ao utilizador é apenas permitido o descarregamento para uso pessoal, pelo que o emprego do(s) título(s) descarregado(s) para outro fim, designadamente comercial, carece de autorização do respetivo autor ou editor da obra.

Na medida em que todas as obras da UC Digitalis se encontram protegidas pelo Código do Direito de Autor e Direitos Conexos e demais legislação aplicável, toda a cópia, parcial ou total, deste documento, nos casos em que é legalmente admitida, deverá conter ou fazer-se acompanhar por este aviso.

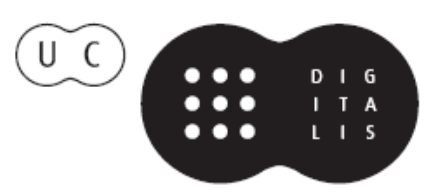



Tendo como pano de fundo as Comemorações dos seus 500 anos, a Biblioteca Geral da Universidade de Coimbra organizou um Congresso Internacional subordinado ao tema "A Biblioteca da Universidade: permanência e metamorfoses", que teve lugar nos dias 16, 17 e 18 de janeiro de 2014, no auditório da Reitoria da Universidade de Coimbra.

O objetivo maior desta reunião científica foi o de refletir sobre o presente e o futuro das bibliotecas que servem públicos universitários. Numa outra vertente, procurou chamar-se a atenção para a importância de que a Biblioteca se reveste, tendo em vista o progresso do conhecimento técnico e científico. Por último, o Congresso pretendeu instituir-se como oportunidade de reflexão prospetiva e como lugar de encontro entre as sensibilidades de todos os que trabalham profissionalmente com livros e com outros suportes de natureza bibliográfica.

Nesse sentido, foram apresentadas Conferências, Mesas Redondas e sessões de Testemunhos em torno de temas como o valor das bibliotecas universitárias, a biblioteca universitária em contexto; as mudanças e os desafios; a biblioteca universitária e a sociedade da informação e conhecimento; o impacto do acesso aberto na comunidade científica, e as bibliotecas digitais. 


\section{LUÍS REIS TORGAL}

Universidade de Coimbra

\section{A B I BLIOTECA E O MEU MUNDO}

A Biblioteca foi um dos mundos científicos e culturais da minha profissão de professor e investigador. Não é que não fosse também o Arquivo, mas, como tenho trabalhado em história das ideias, foi sobretudo o livro o meu principal meio de formação e de estudo.

Mas a Biblioteca Geral não começou para mim no lugar onde hoje está, que sucedeu ao edifício republicano da Faculdade de Letras, que por sua vez ocupou o sempre incompleto Teatro Académico, o qual foi construído ou se ia construindo sobre as ruínas do Colégio de S. Paulo O Apóstolo. Onde requisitei livros pela primeira vez, em 1960 - depois de o ter feito na biblioteca do Liceu D. João III, administrada pelo meu melhor professor de História, Alberto Martins de Carvalho, e nas notáveis bibliotecas ambulantes da Fundação Gulbenkian, na aldeia onde vivi até aos vinte anos -, foi na Biblioteca Joanina ou, mais precisamente, num edifício construído nas suas traseiras, que servia de sala de leitura. Até que um ano depois foi inaugurado o edifício da Biblioteca Geral, integrado na Cidade Universitária salazarista, onde passei a instalar-me com armas e bagagens. Pouca gente que vai à sala de leitura olha com atenção para o painel cerâmico sobre o tema da Universidade, de Jorge Barradas, que nunca deveria deixar de ser apreciado, pois é de um dos artistas mais interessantes da época do Estado Novo.

Claro que percorri muitas outras bibliotecas em Portugal e no Estrangeiro: a Biblioteca da Faculdade de Letras e dos institutos (que nunca deveriam ter desaparecido como estruturas organizadas), a Biblioteca Municipal de Coimbra, a então chamada Biblioteca Nacional de Lisboa (para as bandas do Chiado e depois no Campo Grande), a Biblioteca Pública do 
Porto, a Bibliothèque de la Sorbonne e a Bibliothèque Nationale de Paris (que também conheci em dois lados diferentes e com construções bem distintas), a Biblioteca Nacional de Madrid, a Library of the University of Birmingham, a Biblioteca Nazionale di Roma e não sei quantas mais, por onde passei mais breve tempo, nos Estados Unidos ou no Brasil. Todavia, o meu mundo esteve, sobretudo, centrado na Biblioteca Geral da Universidade de Coimbra. Aí passei horas e dias, a ler, a investigar, a pensar, a escrever..., ali encontrei amigos, conversei com bibliotecários e funcionários (como os recordo com gosto!). Fiz dela um dos meus centros da carreira universitária (de estudante e docente), de cerca de cinquenta anos, e da minha vida, para já com mais de setenta.

Pode dizer-se que a minha tese de licenciatura e a minha tese de doutoramento (que nos preparavam para a pesquisa e abriam as portas da carreira de professores e investigadores) foram ali construídas, tendo, no último caso, ao lado, nos boxes da galeria, o meu grande amigo Doutor Joaquim Ferreira Gomes e também as minhas colegas sempre presentes Maria Manuela Ribeiro, Maria Helena Coelho e muitos outros, com quem discutia nos intervalos do estudo, sobre tudo e nada. Sim, porque a biblioteca é também um lugar de convívio e de tertúlia cultural, científica e até política (recorde-se o significado do "Grupo da Biblioteca Nacional"). E foi, por outro lado, em bibliotecas universitárias estrangeiras abertas ao leitor, em que podia percorrer à vontade os seus depósitos, onde podia procurar os próprios livros nas estantes, e outros, até mais importantes, que ali estavam próximos, que consegui em menos tempo construir capítulos inteiros de obras que vim a escrever ou em que vim a colaborar.

$\mathrm{O}$ que se tem perdido com a falta do contacto material com o livro e, no caso de se tornar uma obsessão, com o livro digitalizado e on line, ou até com o jornal, ou ainda com as redes sociais da internet! Ganho também? Sem dúvida. Como é fácil agora descobrir um livro ou um autor numa biblioteca, encontrar uma frase que sabemos de cor e que está num livro que esquecemos ou desconhecemos, construir uma bibliografia sobre um tema, tirar uma dúvida com um colega ou um especialista que nem conhecemos...! Porém, tem-se deixado de lado um certo universo de saber e de debate, mesmo aquele que é nosso, a nossa biblioteca pessoal, 
que construímos à custa do nosso dinheiro, que gastámos e gastamos em livros (agora menos, porque nos tiraram parte do nosso vencimento ou da nossa pensão), livros que ocupam os nossos escritórios, as nossas salas, os sótãos das nossas casas e até as garagens, sempre com o drama não só de perguntarmos onde os arrumar, mas para onde irão depois da nossa vida. Sobretudo, depois de sabermos que muitos livros dos nossos colegas, que foram deixados ou vendidos por preços simbólicos às instituições onde ensinaram ou que lhes eram próximas, se encontram encaixotados em parte incerta... Por isso alguns de nós, agora, os vão deixando em pequenas vilas, cidades ou até aldeias, onde serão (porventura) menos lidos, mas ficarão melhor preservados.

Livros, bibliotecas, livrarias (agora, em alguns casos, depósitos monopolistas de livros, que se vendem como vendem batatas ou perfumes, ordinários ou caros, livros muitas vezes afixados só em "destaque" à custa de pagamentos das editoras, na fúria de ganhar, como sucede com tudo neste mundo capitalista)... - mundos de realidades e de ilusões, no universo de paradoxos em que vivemos.

Homenageemos a BGUC, os seus directores, bibliotecários e funcionários e ouçamos os testemunhos da Doutora Maria Manuela Delille e do Doutor Fernando Taveira. Cada um, a seu modo, tem feito do livro parte importante da sua vida. 
José Augusto Cardoso Bernardes é Professor da Faculdade de Letras da Universidade de Coimbra e Diretor da Biblioteca Geral da Universidade

Ana Maria Eva Miguéis é coordenadora do Serviço Integrado das Bibliotecas da Universidade de Coimbra

Carla Ferreira é bibliotecária nos Serviços de Biblioteca e Documentação da Faculdade de Letras da Universidade de Coimbra. 


\section{Série Documentos}

Imprensa da Universidade de Coimbra

Coimbra University Press

2015

C •

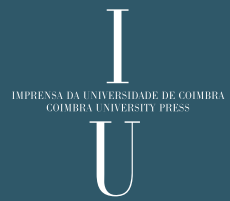

